Erika Süllwold - Das gezeichnete und ausgezeichnete Subjekt 
Erika Süllwold

\section{Das gezeichnete}

\section{und ausgezeichnete Subjekt}

Kritik der Moderne bei Emmy Hennings und Hugo Ball

Verlag J. B. Metzler Stuttgart · Weimar 
Die Deutsche Bibliothek - CIP-Einheitsaufnahme

\section{Süllwold, Erika:}

Das gezeichnete und das ausgezeichnete Subjekt : Kritik der Moderne bei Emmy Hennings und Hugo Ball / Erika Süllwold. Stuttgart ; Weimar : Metzler, 1999 (M-\&-P-Schriftenreihe für Wissenschaft und Forschung) ISBN 978-3-476-45216-0

$$
\begin{gathered}
\text { ISBN 978-3-476-45216-0 } \\
\text { ISBN 978-3-476-04309-2 (eBook) } \\
\text { DOI 10.1007/978-3-476-04309-2 }
\end{gathered}
$$

Dieses Werk ist einschließlich aller seiner Teile geschützt. Jede Verwertung außerhalb der engen Grenzen des Urheberrechtsgesetzes ist ohne Zustimmung des Verlages unzulässig und strafbar. Das gilt insbesondere für die Vervielfältigungen, Übersetzung, Mikroverfilmungen und Einspeicherung in elektronischen Systemen.

M \& P Schriftenreihe für Wissenschaft und Forschung

(C) 1999 Springer-Verlag GmbH Deutschland

Ursprünglich erschienen bei J.B. Metzlersche Verlagsbuchhandlung und Carl Ernst Poeschel Verlag GmbH in Stuttgart 1999 


\section{Inhalt}

Einleitung

1. Das Paar - Skizzen zu einer Profilierung

- Kunst und Leben

- Modernität und Geschlecht

- Identität und Maske

2. Varieté - Ort der Täuschung und Ent-täuschung

2.1 Das „Leben aus dem Stegreif“ und die „Barbarismen des Kabaretts“"

2.2 Das Bündnis von Varieté und Moderne

2.3 Weibliche Erfahrungswelt

- Die Frau im Varieté: girl oder grande dame

- Wege des Erkennens: das Sehen und der Traum 68

2.4 Männliche Erfahrungswelt

- Verschieden als Künstler: Flametti und Herr Meyer

- Cabaret Voltaire

3. Schuld und Verantwortung der Intelligenz -

Hugo Balls Auseinandersetzung mit dem Ersten Weltkrieg

3.1 Demobilmachung

3.2 „Zur Kritik der deutschen Intelligenz“ - Projekt einer Umwälzung

- Revision der Geschichte: die deutsche Sonderentwicklung als Ausweis einer zerstörerischen Moderne

- Revision der Heroen: mit „Enthusiasmus“ gegen die ,deutsche Mentalität"

- Organ der Konversion: die „Kirche der Intelligenz“

- Unterlegener Anarchismus: Kollektivbewußtsein und Rebellion

3.3 Politische Theologie

- Katholizismus: Form der Macht und Form der Therapie

- Auf der Suche nach einer neuen Rolle des Intellektuellen: Gnostiker, Mönch, Priester

- Martyrium: Zerstörung und Rettung des Subjekts 
4. Krieg als Verbrechen -Emmy Hennings' Auseinandersetzung mit der Logik maschineller Gewalt

4.1 Pazifismus

4.2 „Gefängnis" - Parabel von Krieg und Revolution

- Expressionistischer Bericht

- Freiheitsentzug

- Panorama der Maschine

- Gefährtinnen

- Weibliche Aktion

- Einsicht in Schuld

Exkurs

Allegorie des Militarismus: Kafkas Bestrafungsmaschine

5. „Das Brandmal“ - Lebensbeschreibung der Frau

5.1 Wendezeit

5.2 Ich als Beruf - ein Versuch

- In der Verwandlung: die Konvertitin

- Wechsel der Perspektiven: die Stigmatisierte

- In der Gesellschaft: die Schauspielerin

- In der Gewalt: die Frau

- Im Sperrbezirk: die Prostituierte

- Utopie und Realität: Allgemeingut und Freiwild

- Liebe und Leidenschaft: das gefährdete autonome Subjekt

6. „Die Flucht aus der Zeit“ autobiographische Konstruktion des Mannes

6.1 Autor und Zeitzeuge

- Sichbekennen und Sichobjektivieren in der Kunst

- Flucht als Gegenwehr im Leben

6.2 Persönlichkeit statt Öffentlichkeit

- Gesellschaftliche Desintegration und moralische Verpflichtung

- Versagen der Diskurse

- Wandlung und „Definitives“

Biographische Hinweise 